\title{
INTERCULTURALIDADE NA EDUCAÇÃO ESCOLAR INDÍGENA NA PERSPECTIVA DECOLONIAL - O CASO DA CEI RAIMUNDO LOPES NA TERRA INDÍGENA GUAJAJARA EM GRAJAÚ - MA
}

\author{
INTERCULTURALITY IN INDIGENOUS SCHOOL EDUCATION FROM THE \\ DECOLONIAL PERSPECTIVE - THE CASE OF CEI RAIMUNDO LOPES \\ IN THE GUAJAJARA INDIGENOUS LAND IN GRAJAÚ - MA
}

Samuel Correa Duarte ${ }^{1}$

http://orcid.org/0000-0003-3169-3383 http://lattes.cnpq.br/5350906272443743

\section{Taywan Morais Clemente Guajajara² \\ https://orcid.org/0000-0002-3338-9847 \\ http://lattes.cnpq.br/5423754764652969}

Recebido em: 13 de abril de 2020

Aprovado em: 8 de junho de 2020

\begin{abstract}
RESUMO: No presente estudo destacamos as práticas educativas no contexto da etnia Guajajara/Tenetehar residente nos limites da cidade de Grajaú-MA, com pesquisa de campo na aldeia "Bacurizinho". De acordo com informações da SESAI, a referida comunidade é constituída por aproximadamente 800 habitantes distribuídos numa área de 82.423 ha, que foi reconhecida como terra indígena por meio do Decreto 88.610 de 11 de agosto de 1983. A pesquisa foi realizada exclusivamente com professores que atuam no CEI Raimundo Lopes. As questões que nortearam a pesquisa versaram sobre três eixos: 1 . Os processos pedagógicos no contexto escolar local dialogam com a realidade cultural circundante? 2. Como os profissionais de educação atuantes na comunidade lidam com o duplo desafio de preservar e valorizar a cultura local e ao mesmo tempo instruir na cultura abrangente da sociedade brasileira? Como a conjugação de saberes, tradição e organização política pode ser eficaz na resistência frente à colonização cultural? Espera-se que com essas questões, em diálogo com as teorias decoloniais de Mignolo (2008; 2017), Quijano (1992; 2005), Rivera-Cusicanqui (2010), Escobar (2003; 2005) et alli permita (re)pensar os processos de (re)produção da vida material e cultural em contexto de sociedade tradicional indígena.
\end{abstract}

Palavras-chave: Educação Indígena; Prática Docente; Diversidade.

\footnotetext{
${ }^{1}$ Professor da Universidade Federal do Maranhão, Campus Grajaú. Bacharel em Ciências Sociais pela Universidade Federal de Minas Gerais, área de concentração: Sociologia. Mestre em Ciência Política pela Universidade Federal de Minas Gerais, área de concentração: Política Internacional e Comparada. Mestre em Desenvolvimento e Planejamento Territorial pela Pontifícia Universidade Católica de Goiás. Doutorando em Sociologia pela Universidade Estadual do Ceará. E-mail: samuelcorrea.duarte@gmail.com.

${ }^{2}$ Liderança indígena Tenetehar/Guajajara. Discente do Curso de Licenciatura em Ciências Humanas - Geografia, UFMA Campus Grajaú. E-mail: taywanmorais@gmail.com.
} 


\begin{abstract}
In the present study, we highlight educational practices in the context of the Guajajara / Tenetehar ethnic group residing on the outskirts of the city of Grajaú-MA, with field research in the village "Bacurizinho". According to information from SESAI, this community consists of approximately 800 inhabitants distributed over an area of 82.423 ha, which was recognized as indigenous land by Decree 88.610 of August 11, 1983. The research was conducted exclusively with teachers who work in the CEI Raimundo Lopes. The questions that guided the research were based on three axes: 1 . Do the pedagogical processes in the local school context dialogue with the surrounding cultural reality? 2. How do the education professionals working in the community deal with the double challenge of preserving and valuing the local culture and at the same time instructing in the comprehensive culture of Brazilian society? 3. how can the combination of knowledge, tradition and political organization be effective in the local fight against neoliberal logic? It is hoped that with these questions, in dialogue with the decolonial theories of Mignolo (2008; 2017), Quijano (1992; 2005), Rivera-Cusicanqui (2010), Escobar (2003; 2005) et alli, it will allow (re)thinking about the processes of material and cultural life (re)production in the context of traditional indigenous society.
\end{abstract}

Keywords: Indigenous Education; Teaching Practice; Diversity.

\title{
INTRODUÇÃO
}

O presente estudo surgiu da inquietação com relação à condição educacional da comunidade Guajajara no município de Grajaú-MA, dada a vulnerabilidade social e a baixa acessibilidade a políticas públicas específicas que atendam as demandas dessa etnia residente nos limites da cidade de Grajaú-MA. A pesquisa foi realizada exclusivamente com professores que atuam no CEI Raimundo Lopes situada na aldeia "Bacurizinho". De acordo com informações da SESAI, a comunidade da aldeia em tela é constituída por aproximadamente 800 habitantes distribuídos numa área de 83.423 ha, que foi reconhecida como terra indígena por meio do Decreto 88.610 de 11 de agosto de 1983. As questões que nortearam a pesquisa versaram sobre três eixos: 1 . Os processos pedagógicos no contexto escolar local dialogam com a realidade cultural circundante? 2. Como os profissionais de educação atuantes na comunidade lidam com o duplo desafio de preservar e valorizar a cultura local e ao mesmo tempo instruir na cultura abrangente da sociedade brasileira? 3. Como a conjugação de saberes, tradição e organização política pode ser eficaz na resistência frente à colonização cultural?

Do ponto de vista teórico a pesquisa está alicerçada na perspectiva decolonial, como possibilidade de análise crítica da condição social dos povos originários latino americanos; bem como na discussão sobre a educação indígena nas suas principais vertentes. Do ponto de vista metodológico realizamos um estudo de caso, empregando a aplicação de questionários com a subsequente análise do discurso e lexical. Ao final do estudo encontramos que a percepção e demandas dos docentes entrevistados confluem com a agenda de pesquisa e atuação política decolonial. 


\section{DESENVOLVIMENTO}

$\mathrm{Na}$ argumentação de Mignolo (2008:241-242; 249) o pensamento decolonial pretende rediscutir os termos de coexistência entre os grupos dominantes e subalternos, ou seja, colocar em questão o status quo vigente, visto que a matriz colonial de poder se assentou no controle da posse da terra e dos recursos naturais, na expropriação da força de trabalho e do rígido controle político sobre os subalternos. O eurocentrismo jogou aqui papel decisivo na dominação, empregando para isso o "saber-poder" da ciência e o "saber-fazer" do Estado para controlar as populações ameríndias.

Rediscutir as relações de poder no campo da economia, da sexualidade, da subjetividade é papel primordial de uma teoria e prática decolonial. A colonialidade no passado se assentou na retórica religiosa e na conversão ao cristianismo; já na modernidade afirma-se na conversão à civilização ocidental - do controle das almas se passa ao domínio de corpos e mentes. De outro lado, a postura decolonial implica na admissão da co-existência da diversidade cultural e divergência política, de modo que rejeita as visões totalizantes da realidade.

Rivera-Cusicanqui (2010:36) entende que a modernização proposta pelas elites europeias ao longo da história resultou em sucessivos processos de "recolonização" da América Latina. Isso porque a modernidade significou a escravidão dos povos indígenas e um ambiente de espoliação, por um lado; e a condição de uma hegemonia indígena está ancorada na abordagem crítica da noção de território da nação moderna e no entendimento do contexto de um mundo contemporâneo dominado pela lógica do mercado global, por outro lado.

O pensamento decolonial se propõe a ver a realidade a partir das margens do sistemamundo para potencializar novas abordagens contra hegemônicas. Para isso Mignolo (2014:2425) advoga que é preciso descolonizar a democracia. Originada no contexto greco-romano da Antiguidade e adaptada ao modus operandi britânico na Modernidade, consociada ao liberalismo emergente, a democracia enquanto sistema político não é neutra, visto ser resultado da luta pela hegemonia interclasse. O ponto chave é reconhecer que no processo de expansão do Império Britânico também se constituiu o "pacote cultural" da democracia liberal como sistema a ser universalizado. No contexto da pós-modernidade se torna um passo essencial descolonizar a democracia ampliando seu horizonte para acolher as diversidades de ordem racial, sexual, étnica e religiosa, provendo um substrato social à democracia.

Mignolo (2017:3-4) entende que o grande risco a que estamos submetidos na modernidade consiste na dispensabilidade (ou descartabilidade) da vida humana, e da vida em geral, desde a Revolução Industrial até o século XXI. O autor aponta duas orientações gerais da modernidade: 1. uma globalização econômica denominada de forma abrangente de "capitalismo", que depende da ampliação contínua da rede de trocas com a derivação de políticas de alcance global para subsidiar o mercado; 2. como efeito colateral ao processo de globalização emerge uma plêiade de movimentos e instituições que contestam o conteúdo neoliberal do mercado global. Esses movimentos de contestação se valem de matrizes identitárias que permitem integrar os atores em situação de vulnerabilidade - à questão econômica da materialidade do existir se agrega a imaterialidade dos diferentes modos de existir.

Na ótica de Quijano (1992:73) a questão identitária deve ser vista de forma relacional, sendo constituída no processo histórico e na interseção das subjetividades que se articulam no tecido social. A identidade pensada aqui é dotada de dinamismo (do ponto de vista histórico) e polimorfismo (do ponto de vista estrutural), ou seja, oscila conforme a mudança dos eixos tem- 
poral e espacial. No caso latino americano, as identidades originárias somente podem ser compreendidas na relação dual com as identidades dos colonizadores, tanto na forma da hegemonia destes últimos sobre os primeiros quanto na forma das práticas de resistência dos povos subalternos tendo em vista a defesa e difusão dos seus modos de vida típicos.

Quijano (idem:74-76) também elenca alguns elementos que denotam a prática do colonialismo hodierno, a saber: considerar como referência de medida a experiência eurocêntrica para avaliar os usos e casos das sociedades latino-americanas; tomar a posição europeia como nuclear para a percepção da realidade abrangente; empregar as categorias de mundo geradas no âmbito da experiência existencial europeia para compreender a realidade do universo póscolonial; adotar o critério de verdade e validade da racionalidade constituída pela sociedade colonizadora; induzir o colonizado a ver o mundo pelo prisma de quem o colonizou. Desconstruir essas práticas constitui uma agenda de luta decolonial, que inclui a crítica ao modelo europeu de nação, o qual, uma vez imposto aos povos ameríndios, gerou um processo de homogeneização pelo alto contra as tradições nativas na modernidade.

Mas o que é a "modernidade"? Na percepção de Escobar (2003:55-56) a modernidade reúne as seguintes características: surge na Europa do século XVII derivada de processos que incluem a Reforma Protestante, o Iluminismo e a Revolução Francesa; apresenta certa engenharia institucional que inclui o Estado-nação e a separação Estado/Igreja; perpassada por dinâmicas como a compressão espaço/tempo e o distanciamento espaço/lugar; a crescente racionalização do mundo da vida, o fortalecimento do individualismo como ideologia dominante e a centralidade do Estado como meio técnico do mundo administrado; a ascensão da noção de "homem universal" como portadora de direitos e conhecimentos, bem como "entidade" desvinculada das esferas natural e espiritual.

Lander (1993:4-5) nos adverte que a lógica cartesiana, raiz da ciência moderna, leva a uma ruptura ontológica entre razão e mundo da vida que produz uma realidade morta. A ciência moderna, na percepção do referido autor, é um epifenômeno da cultura europeia colonizadora, prenhe dos seus arquétipos e aparelhos de dominação - no seu escopo somente o discurso pretensamente racional de matriz eurocêntrico seria válido e teria abrangência universal. Por isso no processo colonial não bastava ocupar o território, mas era preciso também colonizar as mentes. Tomada como referência unilateral da evolução histórica, a Europa se ergueu como centro difusor da cultura e ciência e assim as populações colonizadas são postas como um ponto de fuga no horizonte da humanidade. De acordo com Borsani (2010:5;10) o "cogito" cartesiano tem como duplo o "ego conquiro", a lógica da submissão do outro pelas relações de poder. A resistência no contexto da subalternidade precisa ir ao encontro das formas de imperialismo epistêmico na busca de erigir saberes autônomos, reinterpretar e ressignificar a realidade tomando como perspectiva as vivências nativas e suas expressões.

Quijano (2005:17) destaca a produção de um novo padrão de poder na modernidade que toma a raça como meio de dominação social global. Na visão do autor a própria ideia de raça é a categoria fundante da modernidade. Isso porque o argumento racial permite articular as relações de dominação construídas pela assimetria de poder com o discurso da hierarquia natural das raças. Derivado disso, a ideologia da raça sustenta que as desigualdades de posição social coincidem com a distribuição de poder inter-racial porque a natureza das raças apresenta desenvolvimento assimétrico. Na prática, essa ideologia abriria caminho para a dominação dos povos ameríndios, a expropriação de suas terras e aculturação de suas populações.

A resposta "decolonial”" à percepção "moderna" da realidade para Escobar (2003:60) reside 
na afirmação dos seguintes termos: situar as origens da modernidade no processo de conquista da América e o controle do Atlântico com o respectivo processo de dominação e extermínio das populações ameríndias; a percepção da passagem do mercantilismo ao capitalismo global como processo de constituição de um abrangente sistema de exploração das sociedades periféricas; a desconstrução do argumento universalista da globalização ante a percepção de que a mesma se constitui em projeto de poder imperialista; a rejeição ao processo de constituição do espaço pós-colonial como sociedades subalternas; a crítica ao eurocentrismo do conhecimento emanado pela díade modernidade/colonialidade - a denúncia da confusão entre um suposto saber universal e a posição hegemônica euro-americana.

Na contraposição desse processo de colonização em escala global, Escobar (2005:69-70) enfatiza que o "lugar" poder ser visto como espaço de experiência e pertencimento cuja conexão é recriada cotidianamente nas interações sociais. Esse lugar se situa na interseção da cultura e natureza, articulando-se com a identidade e história de vida dos sujeitos. Se por um lado a globalização enfatiza os fluxos, o consumo e o domínio do capital, a dinâmica do lugar por sua vez reafirma a cultura local e o bem-viver dos povos tradicionais. Assim o lugar pode ser visto como o "outro" da globalização, sua antítese e antídoto.

Aqui se destacam o que Escobar (2005:72-73) denomina "modelos locais" da natureza, que se constituem a partir da elaboração de epistemes nativas derivadas dos saberes tradicionais (compreender) e sua articulação com os diferentes modos de apreensão do meio ambiente enquanto base existencial (bem viver). A dicotomia que se estabelece com a racionalidade capitalista é a recusa em se apropriar da natureza (dominar) e viver da natureza (explorar) para afirmar o (com)viver como parte do meio ambiente.

Escobar $(2015: 91$; 94) questiona por que as terras indígenas despertam tanto interesse econômico e político; qual a razão da violência contra os povos indígenas. A resposta reside na dinâmica do capital global e nacional - a visão da terra como "recurso natural" passível de plena exploração. Diante disso também se faz necessário perguntar: por que os povos indígenas resistem? Aqui chave consiste na percepção da terra como lugar de existência material e simbólica - a visão da natureza como parte da identidade. Nesse quesito, as estratégias de resistência apresentam quatro vetores: 1 . Potencializar o projeto de vida das comunidades com base na cosmovisão nativa; 2. Promover a defesa do território como espaço de vivência na perspectiva étnico-territorial; 3. Incentivar a organização coletiva de apropriação e controle do território com base na segurança alimentar e na autonomia; 4. Prover a formação e inserção em redes transnacionais de solidariedade e defesa mútua dos povos tradicionais.

O resgate da noção de "lugar" como anteparo existencial, longe de ser um anacronismo, é uma operação de contra força ante a hegemonia do capital global e da assimetria de poder entre as cidades globais e as periferias sociais - onde se situam as comunidades tradicionais. Repensar a realidade a partir da articulação homem/natureza implica em recuperar os saberes tradicionais que operam nessa articulação sem alienar os termos da interação - na base da cultura local estão as trocas do homem com seu meio ambiente.

Podemos agora avançar para a discussão sobre a educação escolar indígena em perspectiva decolonial. De acordo com Abbonizio e Ghanem (2016:889-890; 895) as pesquisas na área da educação escolar indígena apontam que as comunidades têm buscado sanar a demanda por educação na interseção dos grupos étnicos e culturais a partir de uma lógica da bricolagem, mesclando elementos da cultura ocidental (a escolarização) e nativa (a relação intergeracional e hábitos locais). O diagnóstico social e histórico da educação escolar permite identificar três 
fragilidades: a primeira é que a escola tradicional tende a confinar alunos e atividades pedagógicas ao espaço físico escolar; a segunda é que a escola tende a relegar as condições reais de existência no tempo presente para focalizar uma projeção de vida futura, tornando-se assim alienada e alienante; terceiro a escola tende a privilegiar saberes supostamente universais e exógenos ao modo de vida das comunidades, desprezando assim os saberes locais. Sendo assim, a educação escolar indígena, deve se basear em três pilares: a participação ativa da comunidade no desenvolvimento do projeto político educacional e na seleção dos docentes; a produção de material didático calcado na realidade social e linguística da comunidade; a indissociabilidade entre ensino e pesquisa como meio para aprofundar a relação entre escola e mundo da vida. O projeto político de escolas indígenas deve buscar a formação técnica levando em conta as ocupações tradicionais da comunidade como a produção de alimentos, manejo da terra, artesanato e práticas culturais bem como o preparo para a inserção na sociedade ampliada do mundo não-indígena.

Candau (2008, 50-52) identifica duas abordagens gerais sobre a questão multicultural. De um lado, a primeira abordagem é "descritiva", o que implica em reconhecer o fato do multiculturalismo e sua especificidade de acordo com tempo e espaço. Sendo assim, descrever é o passo inicial para compreender cada formação multicultural e sua dinâmica - pensar o mundo como ele "se apresenta". Essa abordagem se subdivide em outras duas: 1. a perspectiva "assimilacionista" entende que a emergência de uma cultura hegemônica é típica da própria dinâmica social, tornando "natural" o processo de assimilação das minorias no âmbito das instituições e práticas dominantes. Para a educação isso implica em perceber a ampliação da oferta de vagas como o principal foco de ação, com uma pauta pedagógica unitária tendo a cultura dominante como paradigma. O risco é, em nome de uma igualdade abstrata, se reforçar desigualdades concretas; 2 . a perspectiva "diferencialista" se assenta na afirmação da diversidade e na criação de meios para que se expressem numa chave essencialista que privilegia a composição de grupos homogêneos de partilha e (re)produção cultural. Transposta para a educação, essa visão implica em criar espaços de vivência pedagógica para diferentes segmentos que compõe o mosaico social. O risco inerente é criar "guetos" pedagógicos e reforçar a segmentação social.

De outro lado, a segunda abordagem, que podemos chamar de "prescritiva", implica em pensar o multiculturalismo como uma posição política diante da realidade e do modo que lidamos com a diversidade e a dinâmica social - pensar o mundo como ele "deve ser". Aqui se advoga um multiculturalismo (enquanto fenômeno) de matriz interativa que reforça a interculturalidade (enquanto estratégia) como experiência formativa do ser humano plural, o que se ajusta bem a um projeto de sociedade democrática e inclusiva. Para tanto, seria preciso "desconstruir" os preconceitos que povoam o ambiente escolar, bem como "desnaturalizar" hábitos e comportamentos discriminatórios reproduzidos no cotidiano. De igual modo, é essencial descolonizar os currículos que se aplicam e os tipos de conhecimento que se ensinam nas escolas, de modo a prover um currículo aberto aos saberes tradicionais.

Fleuri $(2003$, 31), por sua vez, descreve três propostas pedagógicas relativas à educação indígena: 1. A proposta pedagógica multicultural que se caracteriza por um modo de aproximar as diferenças étnico-culturais, isolando-as reciprocamente - a convivência democrática entre todos os grupos diferentes; 2 . A proposta pedagógica intercultural que compreende o "diferente" que caracteriza a singularidade e o caráter único de cada sujeito humano - a ação dialógica a partir da evidência da diferença; 3 . A proposta pedagógica transcultural - fundamenta- 
se como elemento transversal já presente em diferentes culturas ou como produto original da hibridização de elementos culturalmente diferentes.

Consoante à agenda da educação intercultural, de acordo com Melia (1999:13) no espaço escolar devemos atentar para: 1. acolher o que as crianças nos dizem na sua alteridade; 2. compreender os sentidos que suas ações e posições assumem no contexto de seus respectivos padrões culturais. A ação pedagógica dos povos tradicionais é centrada na tríade língua, economia e parentesco. Diante disso, a imposição de uma língua geral ou nacional, currículo também nacional e professores não-indígenas para os povos indígenas gera riscos à alteridade e à diferença no processo pedagógico - o silenciamento da identidade nativa na escola. As vulnerabilidades estão relacionadas com o fato de que a língua com palavras indígenas (langue) pode não ser "indígena" (parole) na sua essência; a adaptação de currículos e conteúdos pode ficar reduzida ao campo do folclórico e do óbvio; os professores podem ser cooptados pelo Estado e pelas instituições. Quais as possibilidades de superação desses riscos e vulnerabilidades? A autora aponta a produção livros e cartilhas em língua indígena, a prévia conquista da escrita de cada uma dessas línguas, o currículo adaptado à realidade indígena, principalmente no que tange aos saberes tradicionais, preparação, incorporação e contratação de professores indígenas por parte do Estado e das instituições.

Candau e Koff (2015:331-332; 335-337) abordam os desafios que a escola contemporânea enfrenta, destacando o papel da didática como parte do rol de estratégias para lidar com a realidade e sala de aula. Que fazer diante da fluidez de informações e identidades entre os educandos? Podemos identificar ao menos duas linhas de ação: 1. a primeira consiste em gerar um choque de gestão que torne mais eficiente os processos de avaliação e controle do processo pedagógico numa chave produtivista; 2. a segunda consiste em repensar o formato escolar vigente colocando em discussão como a escola vive o currículo na prática e tudo que se deriva dele (a organização do tempo e espaço escolar, a divisão de papéis e tarefas etc.). Aqui reside a questão do projeto político educacional que desejamos implementar tendo em vista os objetivos estabelecidos para o processo formativo dos educandos e a atuação dos profissionais da educação. O processo de ensino-aprendizagem deve se guiar pela construção da autonomia, a busca pelo autoconhecimento, o respeito às diferenças, o empoderamento dos elementos subalternos, a promoção da autoestima. A prática docente deve buscar conciliar a busca pela igualdade de direitos com a vivência ativa das diferenças. Nesse sentido, do ponto de vista didático deve se valorizar a aula dialógica que oportuniza ao educando expressar seu modo de pensar e agir no mundo.

Souza e Bruno (2017:199-210) questionam a submissão do processo pedagógico a metas que em última instância atestam o sucesso e o fracasso escolar. Como agravante levanta-se a questão da aplicação dos parâmetros da cultura dominante para a formação de alunos indígenas. A diversidade cultural precisa ser reconhecida e incluída na agenda didática da escola - a oralidade, forma típica de transmissão dos saberes tradicionais pode e deve ser associada com o ensino de leitura e escrita que pautam a comunicação científica.

Nesse sentido, Candau (2016:805-808) critica o peso excessivo das avaliações externas sobre o processo de ensino-aprendizagem - no atual momento a educação tem se voltado ao atendimento dessa "cultura avaliativa" ao invés de privilegiar a cultura efetiva na qual está inserida, distanciando assim o processo educativo do mundo da vida. E para garantir o "sucesso" nas avaliações externas o instrumento é uma determinada concepção de gestão pedagógica centrada em mecanismos de controle monitoramento do que se ensina e do que se 
aprende em sala de aula. Ao tratar da educação intercultural, podemos identificar três eixos norteadores: 1. a conexão entre diferenças culturais e a pauta dos direitos humanos - o combate às desigualdades sociais caminha junto com a expansão do direito de voz do subalterno; 2. a proposição de uma visão multicultural aberta que permita a afirmação das identidades; 3 . a busca por formatos escolares dinâmicos e capazes de propor respostas para as questões da pós-modernidade.

Paula (1999) ressalta as seguintes marcas da questão da educação indígena: 1. a existência do binômio intercultural e bilíngüe é considerado como constitutivo da categoria "escola indígena"; 2. antes de a escola ser intercultural, as sociedades indígenas já estão se relacionando com a sociedade não-indígena, desde o momento do contato. 3. o modo como ocorrem essas relações se reflete no cotidiano da escola. A falácia da (in)capacidade indígena para o processo escolar formal precisa ser desconstruída para se (re)pensar "que escola indígena?" atende aos interesses e necessidades dos povos tradicionais.

Silva $(2014,658-660)$ destaca que a educação/socialização praticada pelo indígena tem caráter comunitário, abarcando língua, saberes, hábitos e rituais do grupo no qual a criança indígena está inserida. Como métodos se destacam a observação e a imitação, processos nos quais a criança aprende os fazeres da comunidade. A percepção da criança que emerge na década de 1990 é a de um ser em formação enquanto espaço de intersubjetividades calcado nas experiências derivadas do cotidiano no mundo da vida. A criança indígena, na relação com a natureza e com seus pares, sejam outras crianças ou adultos, estabelece redes de saberes que a integram do ponto de vista cognitivo à realidade que a cerca.

Do processo cultural de socialização da criança indígena, alguns vetores podem ser identificados: a outorga de autonomia para a criança decidir seu curso de ação e buscar o saber; o reconhecimento das múltiplas habilidades da criança; a preocupação com o cuidado com o corpo (exe. estética nativa) e saúde (exe. alimentação); a percepção da criança como ponte entre o mundo físico (material) e o metafísico (espiritual) uma vez que está em fase de transição para o mundo humano; a criança como parte do processo de continua construção dos laços de parentesco que formam a comunidade; a aprendizagem do ser e fazer indígenas na prática e convivência com os adultos.

Guerola (2018:1444-1448) toma como ponto de partida para analisar a educação intercultural o fato da assimetria a que a população indígena está submetida no contexto nacional levando a importantes implicações no ambiente escolar. O poder enquanto fluxo deve circular no interior de uma sociedade civil plural e multicultural. Nesse sentido repensar a escola e a educação a que os povos indígenas têm acesso se faz necessário, tomando como referência o marco cultural das comunidades que reafirmam suas identidades no cotidiano e demanda a expressão dessas também no ambiente escolar. O exercício do poder numa sociedade aberta e plural deve prover a liberdade na construção identitária conjugada com a produção de signos e significados pelos diferentes sujeitos.

A ação do Estado derivado da experiência colonial visa a submissão dos grupos subalternos produzindo nesses um sentimento de impotência. A institucionalidade implica numa performance de habitus com vistas à manutenção de uma imagem e a provisão dos interesses que orientam a instituição. Nesse sentido, cabe questionar se a escola indígena se coloca ao lado da comunidade ou a serviço de um interesse de Estado. Qual a autonomia que a escola indígena tem para prover um ensino adequado à realidade cultural da comunidade na qual está inserida? Sendo a oralidade uma prática central na dinâmica cultural indígena, qual o lugar do 
discurso na prática pedagógica na educação a que os povos indígenas têm acesso?

Pelo exposto, podemos concordar com Delmondez e Pulino (2014, 633) que identificam uma agenda para a educação escolar indígena hoje no Brasil assim organizada: 1. promover a interculturalidade, ou seja, o trânsito entre diferenças e territórios identitários; 2. propiciar aos indígenas o estatuto de sujeitos de direitos de seus próprios saberes; 3. viabilizar a transmissão de sua cultura no arcabouço institucional do Estado democrático brasileiro; 4. permitir o trânsito entre identidade e diferença. O ponto chave é que a escola indígena hoje deve ter como pressuposto oferecer subsídios para que os próprios sujeitos envolvidos no processo de ensino-aprendizagem se apropriem e construam suas próprias metodologias.

\section{MATERIAIS E MÉTODOS}

A presente pesquisa emprega a metodologia do Estudo de Caso como estratégia para coleta de dados e análise. Fachin (2006:45-46) caracteriza o Estudo de Caso como um método intensivo de estudo da realidade que faculta ao pesquisador ao longo da investigação encontrar pistas e descobertas que não seriam visíveis sem um estudo minucioso. A busca por correlações entre as variáveis em escrutínio conduz à formulação de hipóteses com base na relação de causa e efeito. Ao longo do levantamento de dados e coleta de informações a pesquisa de Estudo de Caso provê especial atenção às características compartilhadas pelos entes estudados, sem descuidar de suas especificidades. A análise derivada de um Estudo de Caso pode resultar em inferências abrangentes com respeito à realidade estudada e corroborar efetivamente para a compreensão dos fenómenos sociais.

Na ótica de Gil (2002, p.54-55) o uso do Estudo de Caso em Ciências Sociais cumpre o papel de suturar a ruptura entre o fenômeno, os sujeitos e o seu contexto, problema recorrente em abordagens que sejam unilaterais nas perspectivas estrutural ou individual. Para isso, o Estudo de Caso reúne esforços para examinar situações reais de vida tendo como perspectiva o contexto abrangente. Sendo um método flexível de investigação, o que lhe dá a vantagem de se adaptar bem ao ambiente em que se desenvolve a pesquisa, o Estudo de Caso exige do pesquisador controle rigoroso nos procedimentos para garantir a confiabilidade e qualidade dos dados coletados.

Prodanov \& Freitas (2013, p.60) entendem o Estudo de Caso como um sistema de coleta e análise de informações com vistas a produzir uma abordagem aprofundada do tema selecionado. Deve atentar para o rigor nos procedimentos e a busca pela coerência na descrição e análise dos dados obtidos em campo. O fato de ser uma pesquisa aplicada permite ao Estudo de Caso se adaptar à realidade que é investigada, constituindo um sistema dinâmico capaz de lidar com imprevistos e viabilizar a pesquisa mesmo em condições adversas. O foco recai sobre um fenômeno analisado dentro do seu contexto de ocorrência.

Com vistas à análise dos dados obtidos por meio de entrevistas, dada sua natureza textual, recorremos ao aporte da análise do discurso e da análise lexical. Nesse sentido, Barros (2015:31-32;34) informa que na ótica da linguística, a língua é basicamente um sistema de signos convencionados que transmitem valores, ideias e vivências. Esse sistema de signos pode ser descrito e analisado de forma sistemática. O ponto de partida aqui é a percepção proposta pela teoria saussuriana que distingue língua (conjunto de signos) e a linguagem (discurso), ou seja, entre o código e a semântica. Interessa à pesquisa social em particular analisar o discurso como articulação entre indivíduo e sociedade. A partir das respostas obtidas se construiu nu- 
vens de palavras para representar graficamente os termos chaves encontrados, bem como se agregou a análise léxica para ratificar as informações obtidas.

Silva, Gobbi \& Simão (2005, p.71-72) entendem a análise do discurso como uma técnica voltada para a compreensão das falas declaradas pelos atores sociais levando-se em conta os eixos temporal, espacial e social. Aqui as diretrizes para captar as relações entre ação e estrutura consistem no modo como se elaboram as representações sociais e como estas impactam a dinâmica social. Mayr (2015, p.756) por sua vez destaca a relação entre discurso, instituição e poder. $\mathrm{O}$ foco reside na relação entre estrutura e agência - qual a dinâmica da relação entre os agentes sociais e as instituições que organizam as práticas sociais num determinado campo (ex: as práticas educacionais)? O primeiro ponto é reconhecer o discurso como a linguagem em ação. O segundo ponto é reconhecer que o discurso pode desencadear um circuito de ações e reações que movimenta as partes envolvidas.

Sobre Análise Léxica, Freitas \& Janissek (2000, p.32-34) entendem que a mesma visa mensurar a extensão das respostas, se foram concisas ou difusas; e a análise tem como foco as palavras, ou seja, um estudo do vocabulário que compõe um discurso. O uso de estatística permite descrever o vocabulário e estabelecer correlações acerca do uso terminológico. A Análise Léxica se inicia pela contagem das palavras, a verificação de seu agrupamento em termos de frequência e afinidades. O intuito é extrair os termos que melhor representam o texto. As categorias linguísticas encontradas no texto podem ser classificadas (verbos, substantivos, adjetivos, pronomes, etc) e quantificadas. Com o recurso à análise léxica o pesquisador pode descrever como o texto foi constituído e colocar em evidência as opiniões e intenções contidas no discurso.

Neste ponto temos algumas informações descritivas dos sujeitos participantes da presente pesquisa. Ao todo foram entrevistados via questionário 06 docentes atuantes no Centro de Educação Indígena Raimundo Lopes, na terra Guajajara situada no município de Grajaú Maranhão. Desde grupo, com faixa etária média de 44 anos, distribuído entre 4 mulheres e 2 homens, encontramos um caso com formação no ensino médio, um outro caso em processo de formação superior e os demais com cursos superiores concluídos. O tempo de experiência no magistério dos participantes da pesquisa é condizente com a faixa etária, indicando uma relação duradoura com a sala de aula. A presença de atuação a longo prazo em sala indica demandas acerca de valorização profissional, formação continuada e participação efetiva na operacionalização da oferta educativa.

Tabela 1. Dados pessoais

\begin{tabular}{l|l}
\hline Sexo & Idade \\
\hline Feminino & 38 anos, 44 anos, 53 anos, 59 anos \\
\hline Masculino & 27 anos, 43 anos \\
\hline
\end{tabular}

Tabela 2. Nível e área de formação

\begin{tabular}{l|l}
\hline Nível de instrução & Área de formação \\
\hline Ensino Médio & Magistério \\
\hline Ensino Superior Incompleto & Pedagogia \\
\hline Ensino Superior Completo & Pedagogia, História (2 casos), Matemática \\
\hline
\end{tabular}


Tabela 3. Tempo de atuação no magistério ${ }^{1}$

\begin{tabular}{l|l}
\hline Tempo de magistério & Registros \\
\hline 0 a 10 anos & 5 anos \\
\hline 11 a 20 anos & 14 anos; 19 anos \\
\hline 21 a 30 anos & 22 anos; 23 anos \\
\hline \multicolumn{1}{c}{${ }^{1}$ um entrevistado não informou }
\end{tabular}

A seguir temos informações relativas à parte qualitativa do questionário, através da qual se buscou evidenciar a percepção dos sujeitos participantes acerca de temas relevantes para a prática da educação indígena. O ponto de partida considerado foi captar o que os sujeitos entendem por interculturalidade. Como eixos dominantes temos a relação com a "diversidade" e a noção de que a interculturalidade se "refere" a algo ou uma prática que visa articular a convivência cultural. A interculturalidade é vista como algo importante e um currículo que acolha a diversidade é considerado uma demanda necessária.

Nesse prisma a valorização da língua nativa é um ponto de referencial essencial para a construção do processo de ensino-aprendizagem. Um dos desafios identificados é a adoção de metodologias de ensino adequadas ao ensino intercultural. De igual modo, reivindica-se a inserção dos saberes e conhecimentos indígenas no ambiente e prática escolar, item essencial no contexto da subalternidade para buscar a superação do imperialismo epistêmico.

No campo político, busca-se mobilizar o Estado em sentido reverso àquele que historicamente se destinou, transformando-o de instrumento de opressão em suporte para a emancipação. Nesse sentido, ao poder público, enquanto gestor, caberia prover maior apoio à formação continuada dos docentes com sua subsequente valorização, bem como uma proximidade efetiva com a realidade cultural da comunidade e suas necessidades. Mas seria esse desiderato viável? As informações a seguir nos permitem uma análise dessa questão.

Tabela 4. O que você entende por interculturalidade?

\begin{tabular}{l|l}
\hline Caso & Resposta \\
\hline D1 & Diversidade cultural existente no convívio social e escolar. \\
\hline D2 & $\begin{array}{l}\text { O conhecimento adquirido pelo ser humano que faz parte de uma sociedade da qual é membro, como: a arte, as } \\
\text { crenças, a lei, a moral, os costumes e todos os hábitos. }\end{array}$ \\
\hline D3 & $\begin{array}{l}\text { Refere-se aos vários costumes que vem se mostrando nos dias de hoje. Como em vários lugares, com dirigentes } \\
\text { linguagens se misturando. }\end{array}$ \\
\hline D4 & $\begin{array}{l}\text { Para refere à diversidade cultural, com variadas origens étnicas, línguas diferentes e tradições culturais bem diversi- } \\
\text { ficadas. }\end{array}$ \\
\hline D5 & $\begin{array}{l}\text { É uma diversidade entre a cultura indígenas e outras culturas. E se refere diversidade de cultura que se manifesta na } \\
\text { sociedade atual. E, também expressa o desejo de melhorar a convivência entre seres humanos. }\end{array}$ \\
\hline D6 & O termo interculturalidade se refere à diversidade cultural que se manifesta na sociedade atual. \\
\hline
\end{tabular}

Análise lexical - Este corpus possui 1 documento 125 formas únicas de palavras.

Densidade vocabular: 0.624

Média de palavras por frase: 15.6

Palavras mais frequentes no corpus: diversidade (5x); refere (4x); cultural (3x); sociedade $(3 \mathrm{x})$; atual $(2 \mathrm{x})$ 
Figura 1. Nuvem de palavras T4

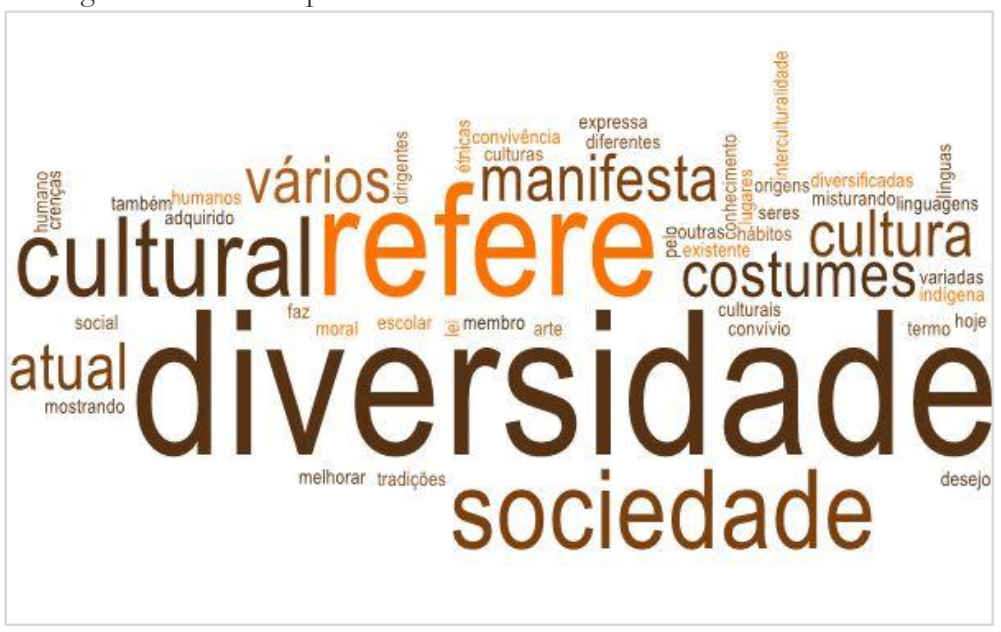

Tabela 5. Você acha que um currículo intercultural é importante para a afirmação cultural do povo indígena?

\begin{tabular}{l|l}
\hline Caso & Resposta \\
\hline D1 & Não, pois acredito que a interculturalidade é uma intervenção que atrapalha no ensino tradicional indígena. \\
\hline D2 & $\begin{array}{l}\text { Sim. Devido a interculturalidade ser entendida de caráter classificatória que limitam a descrever a dinâmica da diver- } \\
\text { sidade cultural. }\end{array}$ \\
\hline D3 & - \\
\hline D4 & Para nós povos indígenas e importante, porque fortalece as nossas tradições culturais. \\
\hline D5 & Sim, porque o estudo é importante para que os indígenas também tenham seus direitos. \\
\hline D6 & Sim, se levarmos em conta a grande diversidade encontrada de pessoas de várias origem e etnias.
\end{tabular}

Análise lexical - Este corpus possui 1 documento 75 formas únicas de palavras.

Densidade vocabular: 0.747

Média de palavras por frase: 15.0

Palavras mais frequentes no corpus: diversidade (2x); importante (2x); indígenas (2x); interculturalidade (2x); acredito (1x)

Figura 2. Nuvem de palavras T5

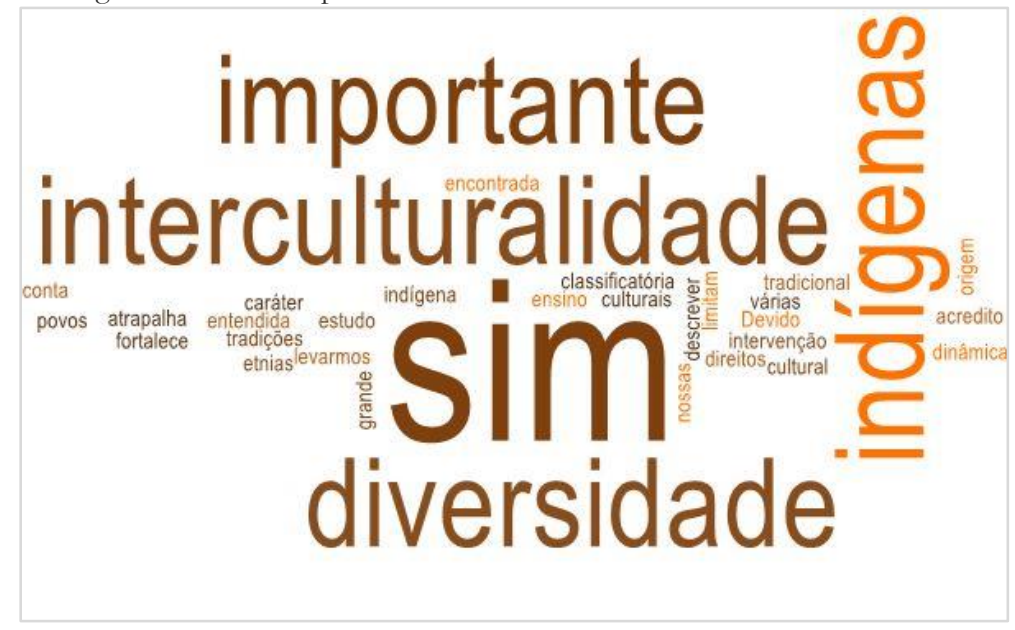

PRACS: Revista Eletrônica de Humanidades do Curso de Ciências Sociais da UNIFAP 
Tabela 6. O que seria na sua visão um currículo intercultural indígena, diferenciado e específico?

\begin{tabular}{l|l}
\hline Caso & Resposta \\
\hline D1 & Um currículo pautado nos saberes indígenas. \\
\hline D2 & $\begin{array}{l}\text { Um currículo que viesse valorizar as línguas indígenas assegurando o direito diferenciado onde se abrigam as disci- } \\
\text { plinas. }\end{array}$ \\
\hline D3 & A tarefa de assegurar direitos dos povos indígenas como reconhecimento e valorização de suas identidades culturais. \\
\hline D4 & Na minha visão, é a valorização de nossas línguas e a importância da nossa identidade. \\
\hline D5 & \begin{tabular}{c} 
É pelo grande crescimento da população indígena que precisamos sempre estar juntos. \\
\hline D6
\end{tabular} \\
$\begin{array}{l}\text { As novas demandas colocadas pelos povos indígenas na busca dos projetos de educação escolar tanto têm dado } \\
\text { novos ritmos. }\end{array}$ \\
\hline
\end{tabular}

Análise lexical - Este corpus possui 1 documento 85 formas únicas de palavras.

Densidade vocabular: 0.753

Média de palavras por frase: 14.2

Palavras mais frequentes no corpus: indígenas (4x); currículo (2x); línguas (2x); povos (2x); valorização (2x).

Figura 3 Nuvem de palavras T6

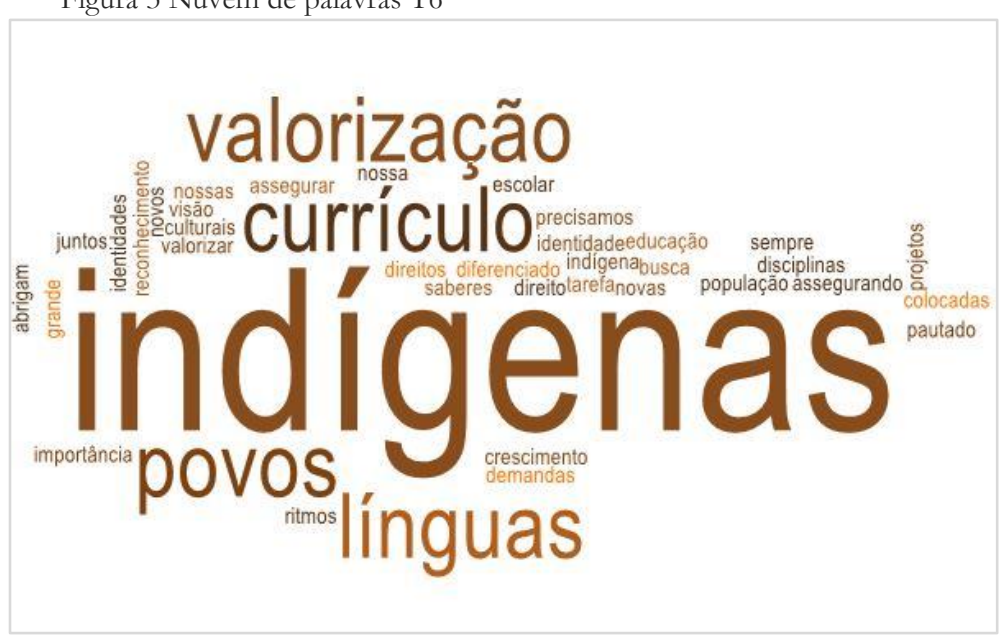

Tabela 7. Quais os desafios que você enfrenta para garantir um currículo intercultural, diferenciado e específico?

\begin{tabular}{l|l}
\hline Caso & Resposta \\
\hline D1 & Metodologia de ensino e linguagem. \\
\hline D2 & Os desafios são a metodologia de ensino e diversidade linguísticas. \\
\hline D3 & - \\
\hline D4 & Eu vou citar só um dos desafios desse currículo é falta de apoio da gestão pública para produção de material didático. \\
\hline D5 & E a coragem de lutar pelos seus direitos que não vá ser violados. \\
\hline D6 & Ainda não se estruturou um sistema que atenda às necessidades educacionais dos povos indígenas. \\
\hline
\end{tabular}

Análise lexical - Este corpus possui 1 documento 63 formas únicas de palavras.

Densidade vocabular: 0.778

Média de palavras por frase: 63.0

Palavras mais frequentes no corpus: desafios (2x); ensino (2x); metodologia (2x); atenda (1x); citar (1X). 
Figura 3 Nuvem de palavras T7

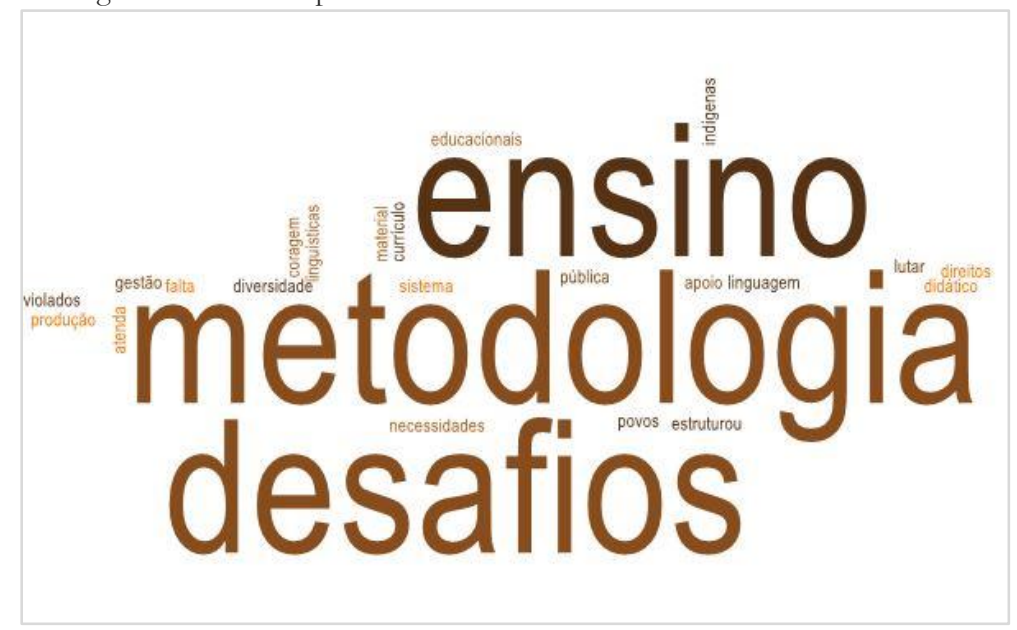

Tabela 8. Como os saberes tradicionais (etnobotânica, etnomatemática, língua nativa, expressões religiosas, identidade corporal etc.) podem ser contemplados na prática de sala de aula?

\begin{tabular}{l|l}
\hline Caso & Resposta \\
\hline D1 & Através da metodologia de ensino. \\
\hline D2 & Através da metodologia de ensino docente. \\
\hline D3 & - \\
\hline D4 & $\begin{array}{l}\text { Sim é primordial os saberes tradicionais como manter a língua, pintura corporal conhecer as plantas medicinais e } \\
\text { outros. }\end{array}$ \\
\hline D5 & E a coragem de lutar pelos seus direitos que não vá ser violados. \\
\hline D6 & Deve ser utilizada para que eles não percam suas raízes. \\
\hline
\end{tabular}

Análise lexical - Este corpus possui 1 documento 57 formas únicas de palavras.

Densidade vocabular: 0.807

Média de palavras por frase: 57.0

Palavras mais frequentes no corpus: ensino (2x); metodologia (2x); conhecer (1x); corporal (1x); culturais (1x).

Figura 4 Nuvem de palavras T8

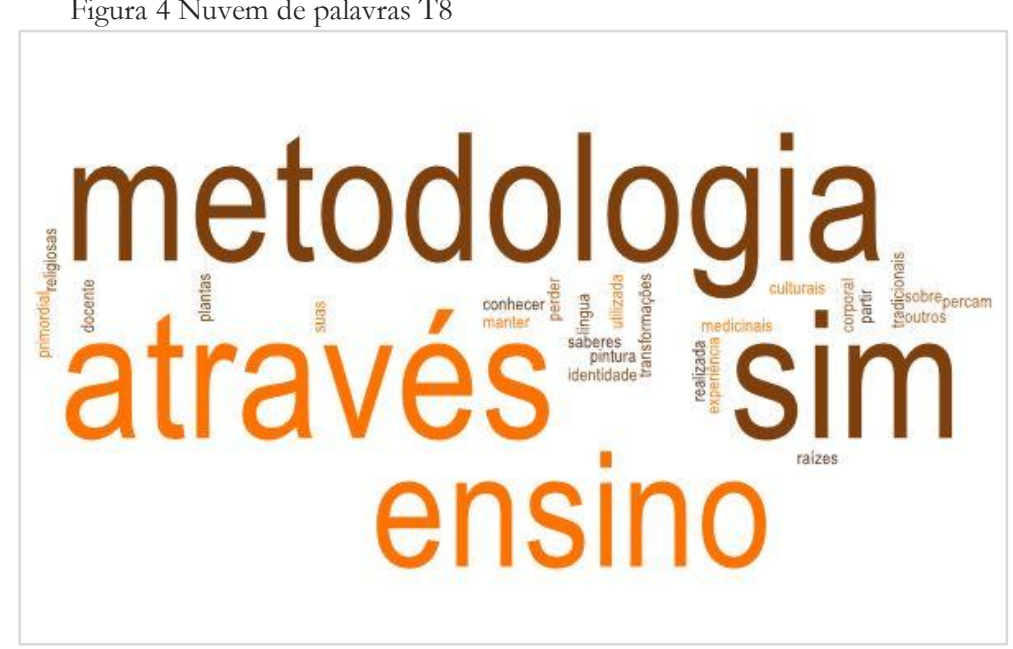

PRACS: Revista Eletrônica de Humanidades do Curso de Ciências Sociais da UNIFAP 
Tabela 9. Como articular a formação para a vida cotidiano na realidade indígena e, também, para a sociedade abrangente (não indígena)?

\begin{tabular}{l|l}
\hline Caso & Resposta \\
\hline D1 & Inserindo no currículo das escolas municipais e estaduais disciplina relacionado aos conhecimentos indígenas. \\
\hline D2 & Ensinando no currículo das escolas municipais e estaduais disciplinas relacionadas aos conhecimentos indígenas. \\
\hline D3 & - \\
\hline D4 & É essencial conhecer a realidade indígena para que a sociedade envolvente conheça sobre os indígenas. \\
\hline D5 & $\begin{array}{l}\text { É uma cultura diferenciada por falta de apoio dos governantes que não dá uma boa condição para que eles possam } \\
\text { alcançar seus objetivos. }\end{array}$ \\
\hline D6 & -
\end{tabular}

Análise lexical - Este corpus possui 1 documento 64 formas únicas de palavras.

Densidade vocabular: 0.734

Média de palavras por frase: 16.0

Palavras mais frequentes no corpus: indígenas (3x); conhecimentos (2x); currículo (2x); escolas (2x); estaduais (2x).

Figura 5 Nuvem de palavras T9

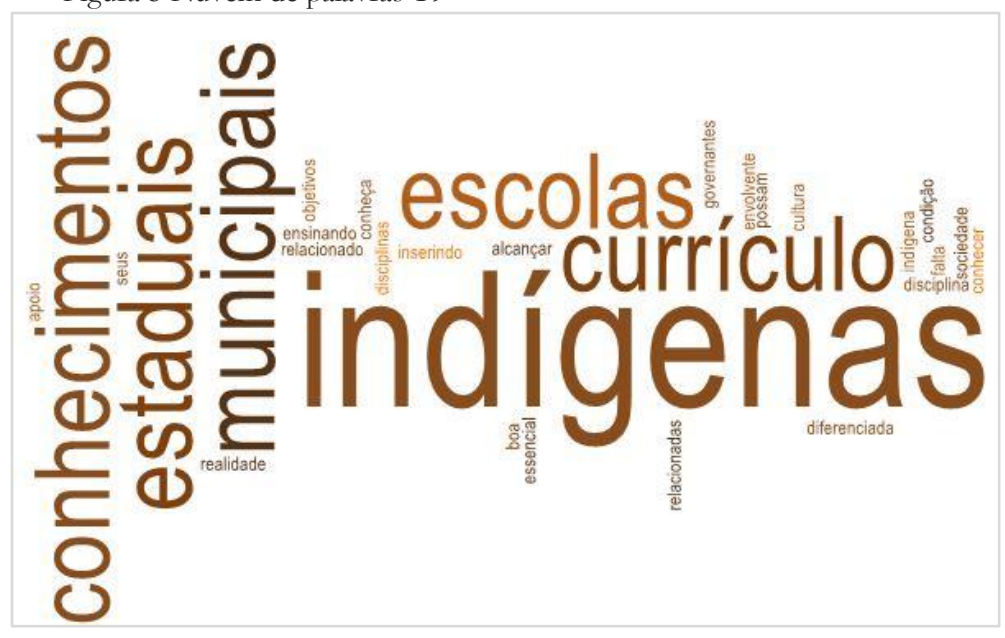

Tabela 10. De que forma a gestão pública poderia aperfeiçoar a oferta de educação escolar indígena?

\begin{tabular}{l|l}
\hline Caso & Resposta \\
\hline D1 & Ofertando melhor a capacitação dos docentes. \\
\hline D2 & Através de capacitações dos docentes. \\
\hline D3 & - \\
\hline D4 & Fazer um encontro dos professores indígenas. \\
\hline D5 & $\begin{array}{l}\text { Dando mais condições e qualidades, porque as dificuldades são muitas e as ofertas são poucas. Hoje o poder público } \\
\text { não tem muito investimento. }\end{array}$ \\
\hline D6 & Tendo consciência de como vive os povos indígenas no contexto escolar. \\
\hline
\end{tabular}

Análise lexical - Este corpus possui 1 documento 51 formas únicas de palavras.

Densidade vocabular: 0.843

Média de palavras por frase: 25.5

Palavras mais frequentes no corpus: docentes (2x); indígenas (2x); capacitação/capacitações (2x); condições (1x). 
Figura 6 Nuvem de palavras T10

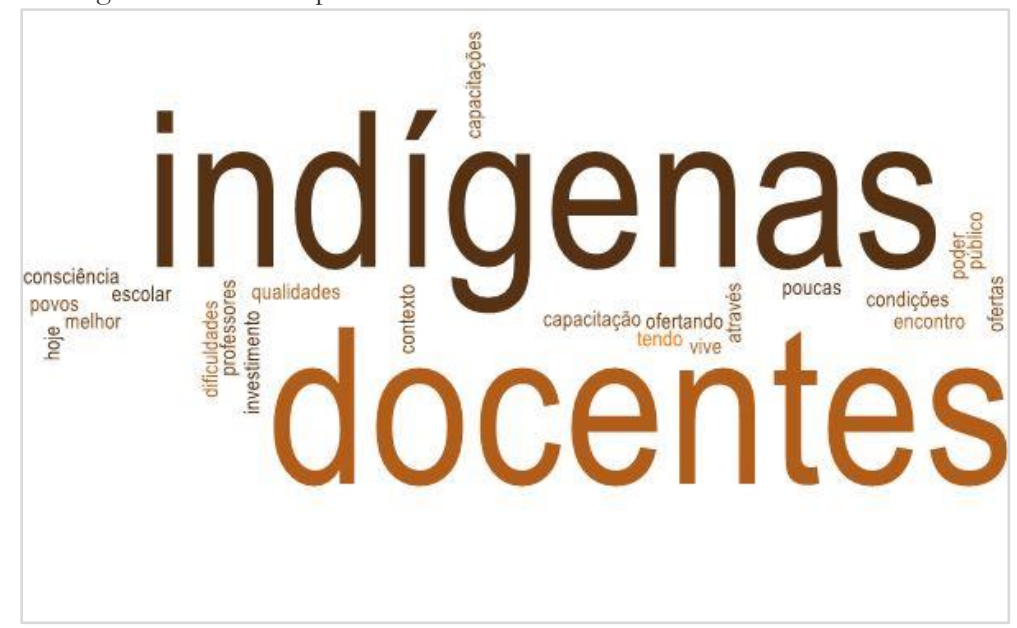

Indicamos o Estado como vetor essencial da mediação na promoção da interculturalidade na Educação. Contudo, podemos derivar da análise das entrevistas que há uma disputa entre Estado e comunidade em torno do projeto político e currículo na educação indígena. Essa disputa evidencia a relevância do projeto político e currículo enquanto recursos de poder controlar o modo de pensar dos povos nativos tem sido desde tempos coloniais uma estratégia recorrente.

A interculturalidade é reconhecida como uma oportunidade de trocas entre a comunidade indígena e a sociedade abrangente, embora os termos de troca possam ser questionados, uma vez que podem tanto permitir a inserção no indígena na sociedade abrangente e o acesso a direitos, quanto gerar aculturação e minar as tradições locais. Sendo assim, a interculturalidade não está livre de contradições, na medida em que se reconhece que se opera uma intervenção nas tradições de um povo a partir da dualidade entre cultura subalterna e cultura dominante. A crítica é que cultura dominante vai à escola indígena como mainstream do saber, enquanto a cultura indígena é ignorada ou inserida como simulacro na escola não-indígena. Os termos das trocas de experiência ou são inexistentes ou insuficientes. Nesse sentido, a cobrança pela inserção da cultura e saberes indígenas no currículo disciplinar das escolas municipais e estaduais é pauta da maior relevância.

Questiona-se em particular qual o espaço que um currículo não adaptado à realidade indígena proverá para abordar temas como economia, sexualidade e subjetividade na perspectiva nativa. A interculturalidade desejável na ótica dos sujeitos da pesquisa implica em promoção de um currículo construído na perspectiva nativa e que valorize principalmente a língua indígena como meio de comunicação e do modo de pensar a realidade.

Ensinar apenas o idioma oficial do Estado sem a contrapartida da valorização da língua nativa pode ser visto como uma estratégia de recolonização dos povos - aculturação continuada. Por isso é que o projeto político das escolas indígenas deve ser construído a partir "das margens", ou seja, na perspectiva da comunidade e não a partir de uma visão externa derivada do Estado. Isso permitiria à educação indígena valorizar o conteúdo identitário local através do currículo.

\section{CONSIDERAÇÕES FINAIS}


Tendo em perspectiva um sistema totalizante como o capital transnacional como se explica a capacidade dos povos tradicionais em sustentar a luta pelos seus territórios, produção e cultura? O argumento de Escobar (1995: 92-95) é que a defesa da vida na ótica dos povos tradicionais opera no campo ontológico, elaborando narrativas que vinculam a existência imaterial à terra mediada pela sua cosmovisão. Nesse sentido, urge fazer a crítica e combate ao projeto moderno de transformação do espaço e da vida em mercadorias bem como a homogeneização das práticas culturais.

A ontologia moderna separa homem e natureza bem como as formas de vida humana, abrindo espaço para a exploração predatória da natureza e do próprio humano. O que não se questiona é que esse mundo do "capitalismo selvagem" se erige contra as formas "selvagens" legítimas de cultura e torna insustentável a manutenção da diversidade cultural e degrada a biodiversidade. Para contrapor-se a essa ontologia o autor propõe pensar uma outra ontologia, na qual nada (seja humano ou não-humano) preexiste às relações que constituem o sujeito em si e para si. Pelo exposto, decorre que a visão ontológica da realidade implica ao menos em quatro fatores centrais: um profundo entendimento da vida, uma estratégia de organização política da luta, uma forte consciência das interconexões globais e uma visão holística da relação homem-natureza.

O trunfo da perspectiva intercultural aplicada à educação é reconhecer que as identidades se constituem na interseção das subjetividades, de modo que é preciso pensar uma educação dinâmica e diversificada tanto no conteúdo quanto nas estratégias didáticas para permitir ao educando dialogar com o mundo da vida a partir da relação ensino-aprendizagem. Mas é preciso ir além de buscar a descolonização do currículo, trazendo para dentro dele: a experiência do modo de vida ameríndio, os saberes tradicionais, os conceitos nativos de compreensão da realidade.

No que diz respeito à educação como processo de socialização, faz-se necessário na educação indígena valorizar o aspecto comunal da sua tradição em contraposição ao individualismo derivado da modernidade ocidental e sua noção abstrata de "homem universal" - o sujeito da história indígena é de carne e osso, espírito vivente. E nessa tópica podemos de um lado romper com a lógica de exploração do homem pelo homem e seu duplo, qual seja, a exploração da natureza pelo homem.

A resistência indígena pela educação passa pela valorização da cosmovisão nativa, o conhecimento abrangente sobre seu território como espaço vital, a promoção da segurança alimentar e a construção de redes de apoio mútuo entre as comunidades indígenas na troca de saberes. A escola indígena não pode ser mais um espaço "fora do lugar" (alienada e alienante com relação à cultural local) pois preciso é que seja construída a partir do "lugar" para a partir desse ponto se disseminar pelos diferentes espaços sociais (como forma de representação legítima das tradições e saberes locais).

Anunciamos no início do presente texto que as questões norteadoras da pesquisa estavam distribuídas em três eixos. Vimos pelo exposto, que no primeiro eixo, como os processos pedagógicos no contexto escolar local dialogam com a realidade cultural circundante, que essa interação se dá em desfavor das tradições locais e dos saberes tradicionais, não contemplados nas políticas educacionais do Estado e seus instrumentos, como o material didático e formação continuada.

No que diz respeito ao segundo eixo, como os profissionais de educação atuantes na comunidade lidam com o duplo desafio de preservar e valorizar a cultura local e ao mesmo tempo 
instruir na cultura abrangente da sociedade brasileira, destacamos a escola indígena como espaço de luta e resistência, em especial tendo em vista a manutenção da língua nativa como forma de acesso e comunicação da cosmovisão que organiza o modo de vida local.

Por fim, no terceiro eixo, como a conjugação de saberes, tradição e organização política pode ser eficaz na luta local contra a lógica neoliberal, depreende-se que a escola indígena exerce uma função social primordial ao se constituir em espaço político de promoção das identidades tradicionais, das quais se derivam as relações entre os homens e destes com a natureza em chave diversa daquela dominante na cultura ocidental capitalista.

\section{BIBLIOGRAFIA}

ABBONIZIO, A.; GHANEM, E. Educação escolar indígena e projetos comunitários de futuro. Educ. Pesqui., São Paulo, v. 42, n. 4, p. 887-901, dez. 2016.

BARROS, T. H. B. Uma trajetória da arquivística a partir da análise do Discurso: inflexões histórico-conceituais [online]. São Paulo: Editora UNESP; São Paulo: Cultura Acadêmica, 2015.

BORSANI, M. E. Razón y conquista: reflexiones decoloniales en torno a pasados límites. Actas IV Jornadas Historia de la Patagonia. Santa Rosa - AR: Universidad Nacional de Pampa, 2010.

CANDAU, V. M. Direitos humanos, educação e interculturalidade: as tensões entre igualdade e diferença. Rev. Bras. Educ., Rio de Janeiro, v. 13, n. 37, p. 45-56, abr. 2008.

Cotidiano escolar e práticas interculturais. Cad. Pesqui., São Paulo, v. 46, n. 161, p. 802-820, set. 2016.

CANDAU, V. M.; KOFF, A. M. N. S. A Didática Hoje: reinventando caminhos. Educ. Real., Porto Alegre, v. 40, n. 2, p. 329-348, jun. 2015.

DELMONDEZ, P.; PULINO, L. H. C. Z. Sobre identidade e diferença no contexto da educação escolar indígena. Psicol. Soc., Belo Horizonte, v. 26, n. 3, p. 632-641, dez. 2014

ESCOBAR, A. "Mundos y conocimientos de otro modo: el programa de investigación modernidad/colonialidad latinoamericano". Tabula Rasa, n. 1, p. 58-86, 2003.

O lugar da natureza e a natureza do lugar: globalização ou pós- desenvolvimento? A colonialidade do saber: eurocentrismo e ciências sociais. Perspectivas latino-americanas. Buenos Aires: CLACSO, Consejo Latinoamericano de Ciencias Sociales, 2005.

. Territorios de diferencia: la ontología política de los “derechos al territorio". Desenvolv. Meio Ambiente, v. 35, p. 89-100, dez. 2015.

FACHIN, O. Fundamentos de metodologia. 5a edição [rev]. São Paulo: Saraiva, 2006.

FLEURI, R. M. Intercultura e educação. Rev. Bras. Educ., Rio de Janeiro, n. 23, p. 1635, ago. 2003.

FREITAS, H. M. R. de; JANISSEK, R. Análise léxica e análise de conteúdo: técnicas complementares, sequenciais e recorrentes para exploração de dados qualitativos. Porto Alegre: Sphinx: Editora Sagra Luzzatto, 2000.

GIL, A. C. Como elaborar projeto de pesquisa. 4. ed. - São Paulo: Atlas, 2002.

GUEROLA, C. M. Cultura vs. estado: relações de poder na educação escolar indígena. Trab. linguist. ap1., Campinas, v. 57, n. 3, p. 1443-1466, set. 2018.

LANDER, E. La colonialidad del saber: euroccentrismo y ciencias sociales: perspectivas latinoamericanas. CLACSO: Buenos Aires, 1993. 
MAYR, A. Institutional Discourse. In: TANNEN, Debora H.; HAMILTON, Heidi E.; SCHIFFRIN, Deborah. The Handbook of Discourse Analysis. Second Edition. Vol. I. Blackwell Publishers Ltd, 2015. pg 755-774.

MELIA, B. Educação indígena na escola. Cad. CEDES, Campinas, v. 19, n. 49, p. 11 17, dez. 1999.

MIGNOLO, W. D. Novas reflexões sobre a "idéia da América Latina": a direita, a esquerda e a opção descolonial. Cad. CRH, Salvador, v. 21, n. 53, p. 237-250, Aug. 2008.

- Democracia liberal, camino de la autoridad humana y transición al vivir bien. Soc.

estado., Brasília, v. 29, n.1, p. 21-44, Apr. 2014.

. Colonialidade: o lado mais escuro da modernidade. Rev. bras. Ci. Soc., São Paulo, v. 32, n. 94, 2017.

PAULA, E. D. de. A interculturalidade no cotidiano de uma escola indígena. Cad. CEDES, Campinas, v. 19, n. 49, p. 76-91, dez. 1999.

QUIJANO, A. Notas sobre a questão da identidade e nação no Peru. Estud. av., São Paulo, v. 6, n. 16, p. 73-80, Dec. 1992.

. Dom Quixote e os moinhos de vento na América Latina. Estud. av., São Paulo, v. 19, n. 55, p. 9-31, dez. 2005.

PRODANOV, C. C.; FREITAS, E. C. de. Metodologia do trabalho científico: métodos e técnicas da pesquisa e do trabalho acadêmico. 2. ed. - Novo Hamburgo: Feevale, 2013. RIVERA-CUSICANQUI, S. Ch’ixinakax utxiwa: una reflexión sobre prácticas y discursos descolonizadores. Buenos Aires: Tinta Lemón, 2010.

SOUZA, I. R. C. S. de; BRUNO, M. M. G. Ainda Não Sei Ler e Escrever: alunos indígenas e o suposto fracasso escolar. Educ. Real., Porto Alegre, v. 42, n. 1, p. 199-213, mar. 2017.

SILVA, C. R.; GOBBI, B. C.; SIMÃO, A. A. O uso da análise de conteúdo como uma ferramenta para a pesquisa qualitativa: descrição e aplicação do método. Organizações Rurais \& Agroindustriais, vol. 7, núm. 1, 2005, pp. 70-81.

SILVA, R. C. da. Participação e aprendizagem na educação da criança indígena. Rev. Bras. Educ., Rio de Janeiro, v. 19, n. 58, p. 655-670, Sept. 2014. 